\title{
Purification of the exopolysaccharide produced by Alteromonas infernus: identification of endotoxins and effective process to remove them
}

\author{
Grivaud-Le Du Alicia ${ }^{1}$, Zykwinska Agata ${ }^{1}$, Sinquin Corinne ${ }^{1}$, Ratiskol Jacqueline ${ }^{1}$, Weiss Pierre ${ }^{2}$, \\ Vinatier Claire ${ }^{2}$, Guicheux Jerome ${ }^{2}$, Delbarre-Ladrat Christine ${ }^{1}$, Colliec-Jouault Sylvia ${ }^{1,{ }^{*}}$ \\ ${ }^{1}$ IFREMER, Lab Ecosyst Microbiens \& Mol Marines Biotechnol, EM3B, Rue lle dYeu, F-44311 Nantes \\ 3, France. \\ ${ }^{2}$ Univ Nantes, Inserm UMRS 1229, UFR Odontol, 1 PI Alexis Ricordeau, F-44042 Nantes 1, France.
}

*Corresponding author : Sylvia Colliec-Jouault, email address : Sylvia.Colliec.Jouault@ifremer.fr

\begin{abstract}
:
Alteromonas infernus bacterium isolated from deep-sea hydrothermal vents can produce by fermentation a high molecular weight exopolysaccharide (EPS) called GY785. This EPS described as a new source of glycosaminoglycan-like molecule presents a great potential for pharmaceutical and biotechnological applications. However, this unusual EPS is secreted by a Gram-negative bacterium and can be therefore contaminated by endotoxins, in particular the lipopolysaccharides (LPS). Biochemical and chemical analyses of the LPS extracted from $A$. infernus membranes have shown the lack of the typical LPS architecture since 3-deoxy-d-manno-oct-2-ulopyranosonic acid (Kdo), glucosamine (GlcN), and phosphorylated monosaccharides were not present. Unlike for other Gramnegative bacteria, the results revealed that the outer membrane of $A$. infernus bacterium is most likely composed of peculiar glycolipids. Furthermore, the presence of these glycolipids was also detected in the EPS batches produced by fermentation. Different purification and chemical detoxification methods were evaluated to efficiently purify the EPS. Only the method based on a differential solubility of EPS and glycolipids in deoxycholate detergent showed the highest decrease in the endotoxin content. In contrast to the other tested methods, this new protocol can provide an effective method for obtaining endotoxin-free EPS without any important modification of its molecular weight, monosaccharide composition, and sulfate content.
\end{abstract}

Keywords: Marine Alteromonas infernus, Bacterial exopolysaccharide, Endotoxin, Characterization, Purification, Fermentation, Process 


\section{Introduction}

In recent years, the increasing demand for natural polymers in pharmaceutical, food or other industrial applications has led to a remarkable interest in polysaccharides produced by microorganisms. In particular, due to their capacity to produce bioactive compounds, the study of bacteria from marine origin is becoming an important research topic (Laurienzo 2010). Many known marine bacteria produce high molecular weight (HMW) extracellular glycopolymers, so called exopolysaccharides (EPS), and some of them display unique properties (Guezennec 2002). Previous studies have shown that some deep-sea hydrothermal vent bacteria, such as Alteromonas and Vibrio species, produce EPS endowed with original structures (Delbarre-Ladrat et al. 2014) and innovative heparin-like properties (Colliec-Jouault et al. 2004). Notably, Alteromonas infernus bacterium, isolated in deep-sea sediments of the Guaymas basin (Gulf of California), secretes a branched HMW GY785 EPS $\left(2 \times 10^{6} \mathrm{~g} / \mathrm{mol}\right)$ with a sulfated nonasaccharide repeating unit (Fig. 1). Recently, a low molecular weight (LMW) oversulfated derivative obtained from the HMW GY785 EPS was demonstrated to enhance the chondrogenic differentiation of mesenchymal stem cells, considered as an attractive source of cells for cartilage engineering (Merceron et al. 2012). More recently, the LMW GY785 EPS derivative was shown to inhibit the establishment of lung metastases in pre-clinical model (Heymann et al. 2016).

A. infernus is a Gram-negative bacterium. Consequently, the EPS produced by this bacterium can be contaminated by different bacterial extracellular molecules such as lipopolysaccharides (LPS), an integral component of its outer cell surface, proteins, nucleic acids (DNA) and/or residual salts. These contaminants, often called pyrogens or endotoxins, can alter the EPS beneficial effect and induce severe side effects. In particular, LPS exhibit a wide range of pathophysiological effects (Wang et al. 2010) and their removal below the nanogram level is a crucial step to prevent from endotoxin shock reactions, tissue injury and even death of host organisms. Nevertheless, if the LPS of many bacteria are well characterized, the LPS produced by Alteromonas spp., and especially those isolated from deep-sea environment, are much less studied (Caroff et al. 2003).

Several methods have been developed for production and purification of EPS (Adam et al. 1995, Anspach et al. 1995, Wilson et al. 2001, Magalhaes et al. 2007). However, these methods result in variable amounts of residual endotoxins along with traces of LPS, protein and nucleic acids. Some endotoxin acceptable limits have been calculated and can be found in the Pharmacopoeia. Because endotoxins have severe adverse effects at low concentrations, their removal from pharmaceutical products is crucial even if it is a laborious step. Although acid or alkaline treatment can be used to inactivate LPS by lipid A removal, these methods can depolymerize biological molecules such as EPS (McIntire et al. 1967). Thus, non-destructive methods for LPS removing are required. Few methods, such as Triton X-114 phase separation or affinity chromatography, led to a significant LPS removal from polysaccharides below the nanogram level (Pier et al. 1978).

In this work in order to efficiently purify the HMW GY785 EPS, we first identified the molecules coproduced with EPS upon A. infernus growth to determine if typical components such as LPS are present. In parallel, LPS directly extracted from bacterial cell membranes were characterized. Then, after different treatments commonly employed to reduce endotoxin level, we determined if the previously identified molecules are still present in EPS batches produced by fermentation. Finally, we optimized a method for developing a 
suitable purification process including different criteria such as: (i) an endotoxin level authorized by the European Pharmacopoeia ( $<0.5$ EU/mg), (ii) minimized degradation of the EPS, (iii) an optimal recovery of the EPS and (iv) a scalable method.

\section{Materials and Methods}

\section{A. infernus cultures for LPS production}

$1.8 \mathrm{ml}$ of $A$. infernus strain (CNCM- I 1628) stored at $-80^{\circ} \mathrm{C}$ was used for the culture. The bacteria were grown in a Zobell marine medium composed of $5 \mathrm{~g} / \mathrm{L}$ of tryptone, $1 \mathrm{~g} / \mathrm{l}$ of yeast extract and $33 \mathrm{~g} / \mathrm{l}$ of aquarium salts. The culture was carried out in an Erlenmeyer flasks (1,000 ml) containing $200 \mathrm{ml}$ of marine medium and placed in an incubator at $30{ }^{\circ} \mathrm{C}$ under agitation. After $48 \mathrm{~h}$, the bacterial cells were isolated from the marine medium by centrifugation (20 min at $8,000 \mathrm{~g}$ ) and freeze-dried.

\section{A. infernus fermentations for EPS production}

GY785 EPS was produced by A. infernus strain in fermenters (301 or 401 of medium) with Zobell marine medium. The carbohydrate source necessary for biosynthesis (glucose $30 \mathrm{~g} / \mathrm{l}$ final concentration) was added at the beginning of the batch culture. Then the culture was placed under controlled conditions (aeration, agitation, $\mathrm{pH}$ and temperature) until the carbohydrate was totally consumed. HMW GY785 EPS secreted into the culture medium was precipitated by ethanol after centrifugation or ultrafiltered and then freeze-dried, as previously described (Rougeaux et al. 1999, Roger et al. 2004).

Extraction of LPS from bacterial cells after fermentation

From freeze-dried bacterial cells, LPS were extracted following classical methods, such as hot phenol/water or phenol/chloroform/petroleum ether extractions, (Galanos et al. 1969).

a. Hot phenol-water $(P W)$ method: $200 \mathrm{mg}$ of bacterial cells were suspended in $5 \mathrm{ml}$ of deionized water. A mixture of hot $\left(65^{\circ} \mathrm{C}\right)$ phenol $(4.5 \mathrm{ml})$ and water $(0.5 \mathrm{ml})$ was added to the suspension and left under stirring at $65^{\circ} \mathrm{C}$ for $30 \mathrm{~min}$. The mixture was then cooled to $5{ }^{\circ} \mathrm{C}$, and centrifuged for $30 \mathrm{~min}$ at $8,000 \mathrm{~g}$. The aqueous supernatant was separated and the phenol layer re-extracted with water $(5 \mathrm{ml})$ followed by centrifugation as described above. The combined aqueous phases and the phenol phase were dialyzed (5 days) against water and freeze-dried.

b. Phenol-chloroform-petroleum ether (PCP) method: $200 \mathrm{mg}$ of bacterial cells were subjected to the extraction mixture $(5 \mathrm{ml})$ of $90 \%$ phenol/chloroform/petroleum ether $(2: 5: 8 \mathrm{v} / \mathrm{v} / \mathrm{v})$, at $10{ }^{\circ} \mathrm{C}$ for $30 \mathrm{~min}$. The mixture was then centrifuged for $10 \mathrm{~min}$ at $5,000 \mathrm{~g}$. The cell pellet was submitted to two more extractions as above. Solvents from the supernatants are evaporated and deionized water is slowly added to the remaining solution to precipitate the LPS. Pellet and supernatants were dialyzed (5 days) against water and freeze-dried. 
Purification treatments applied to GY785 EPS

a. Affinity chromatography: LPS was removed by affinity chromatography on Proteus NoEndo columns (Generon, UK). EPS was solubilized in $0.01 \mathrm{M}$ EDTA at $\mathrm{pH} 7$ and a concentration of $1 \mathrm{mg} / \mathrm{ml}$ and loaded $(20 \mathrm{ml})$ onto the column by centrifugation to obtain a flow rate of $1 \mathrm{ml} / \mathrm{min}(30-45 \mathrm{~min}$ at 100 g). The eluted solution was extensively dialyzed against water before freeze-drying. The resin was regenerated by desorption of the LPS with $1 \%$ sodium deoxycholate (NaDOC) in $0.1 \mathrm{M}$ ammonium bicarbonate solution. In parallel, affinity purification experiments were carried out in batch. EPS was solubilized in EDTA $0.01 \mathrm{M}$ solution $(\mathrm{pH} 7)$ at $1 \mathrm{mg} / \mathrm{ml}$ with $1 \mathrm{ml}$ of NoEndo resin. After 2 days of stirring, the resin was removed by centrifugation (30 min at 10,000 g). The resulting supernatant was dialyzed and freeze-dried.

b. Anion exchange chromatography: EPS was dissolved in $0.5 \mathrm{M}$ sodium acetate (pH 6) at a concentration of $1 \mathrm{mg} / \mathrm{ml}$. $500 \mathrm{mg}$ of DEAE-Sephadex resin, pre-equilibrated with sodium acetate at $\mathrm{pH} 6$, was added to $50 \mathrm{ml}$ of EPS solution, and the solution was stirred $2 \mathrm{~h}$ at room temperature. The resin was poured in a Poly-Prep chromatography column. EPS was eluted with a linear gradient of $0.5 \mathrm{M}$ sodium acetate with $\mathrm{NaCl}(50 \mathrm{ml}, 0$ to $1 \mathrm{M})$ at $2 \mathrm{ml} / \mathrm{min}$. Each fraction was collected, dialyzed against water and freeze-dried.

c. Bligh and Dyer extraction: EPS was dissolved in 0.01 M EDTA solution ( $\mathrm{pH} 7)$ at a concentration of $10 \mathrm{mg} / \mathrm{ml}$. Five volumes of chloroform/methanol (2/1, v/v) were added and the mixture was stirred for $4 \mathrm{~h}$ at room temperature. After centrifugation, the organic phase containing LPS was discarded. Aqueous phase containing EPS was precipitated by cold ethanol and collected by centrifugation. The obtained EPS was subjected to two other extractions as described above before being extensively dialyzed and freeze-dried.

d. Triton $\mathrm{X}-114$ extraction: EPS was dissolved at $1 \mathrm{mg} / \mathrm{ml}$ in water or 0.01 M EDTA solution (pH 7) and Triton X-114 was added to a final concentration of $1 \%(\mathrm{v} / \mathrm{v})$. After cooling on ice, the solution was stirred at $4^{\circ} \mathrm{C}$ for $1 \mathrm{~h}$ and incubated at $37^{\circ} \mathrm{C}$ in a water bath for $1 \mathrm{~h}$ to induce phase separation. The upper aqueous phase containing EPS was carefully removed after centrifugation (10 $000 \mathrm{~g}, 30 \mathrm{~min}$, $30^{\circ} \mathrm{C}$ ) and subjected to Triton X-114 phase separation for at least two more cycles with $5 \%(\mathrm{v} / \mathrm{v})$ Triton $\mathrm{X}-114$. To the resulted aqueous phase, $\mathrm{NaCl}(2 \%$, w/v final concentration) and cold ethanol (3 volumes) were added to precipitate the purified EPS. After dissolution in water, the obtained EPS was extensively dialyzed to eliminate traces of detergent and salt, and freeze-dried (Adam et al. 1995).

e. Sodium deoxycholate (NaDOC) extraction: EPS was dissolved in $0.05 \mathrm{M}$ Tris $\mathrm{HCl}$ buffer containing $0.1 \mathrm{M} \mathrm{NaCl}(\mathrm{pH} 7)$. $\mathrm{NaDOC}$ was added at $2 \%(\mathrm{w} / \mathrm{v})$. The mixture was incubated at $65^{\circ} \mathrm{C}$ for $15 \mathrm{~min}$ and then cooled on ice. EPS solution was acidified with acetic acid (20\%) to pH 5 and centrifuged (8000 g, $30 \mathrm{~min}$ ) to precipitate LPS and NaDOC. The supernatant containing EPS was extensively dialyzed against water and freeze-dried (Kachlany et al. 2001).

Analytical techniques

a. Characterization of LPS extracted from A. infernus bacterial cells: Elemental analyses were performed by the Central Micro-analysis Department of the CNRS at Gif/Yvette (France) for carbon, hydrogen, 
nitrogen and sulfur contents and by the Central Micro-analysis Department of the CNRS at Villeurbanne (France) for phosphorus content. Monosaccharide and fatty acids compositions were determined as described by Bohin et al. (Bohin et al. 2005). Briefly, $200 \mathrm{mg}$ of dried samples or monosaccharide and fatty acid standards were submitted to acid methanolysis with $\mathrm{MeOH} / \mathrm{HCl} 0.5 \mathrm{M}$, for $20 \mathrm{~h}$ at $80^{\circ} \mathrm{C}$. After drying under a stream of nitrogen, $200 \mu \mathrm{L}$ of acetonitrile and $25 \mu \mathrm{L}$ of heptafluorobutyric anhydride (HFBA) were added. The samples were heated for $15 \mathrm{~min}$ at $150^{\circ} \mathrm{C}$. After evaporation of the reagents under a stream of nitrogen, samples were taken up in $250 \mu \mathrm{L}$ of dichloromethane, and $1 \mu \mathrm{L}$ was injected into the GC-MS apparatus, on a VF-1ms capillary column. The temperature was set up at $90^{\circ} \mathrm{C}$ for $3 \mathrm{~min}$, then increased by $5^{\circ} \mathrm{C} / \mathrm{min}$ up to $260^{\circ} \mathrm{C}$ and held for 20 min. Electrospray spectra were obtained at $70 \mathrm{eV}$ at $230^{\circ} \mathrm{C}$.

b. Determination of LPS content in EPS batches: The amount of LPS was determined by direct transmethylation of the fatty acids and GC-MS analysis of the obtained fatty acid methyl esters (FAMES) derivatives (Tirsoaga et al. 2007). $10 \mathrm{mg}$ of EPS, and a known amount of C17:0 (used as internal standard) were dissolved in $0.5 \mathrm{~mL}$ of $\mathrm{HCl} / \mathrm{MeOH} 0.6 \mathrm{M}$, and heated at $80^{\circ} \mathrm{C}$ for $20 \mathrm{~h}$. After cooling, $1 \mathrm{~mL}$ of water was added. FAMES were extracted twice by $2 \mathrm{~mL}$ of hexane. The organic layer was reduced under $\mathrm{N}_{2}$ and subjected to GC using an Agilent 6890 series gas chromatograph equipped with a VF-1ms capillary column and electrospray Agilent 5973 Network mass spectrometer detector. The temperature was set up at $90^{\circ} \mathrm{C}$ for $2 \mathrm{~min}$, then increased by $2^{\circ} \mathrm{C} / \mathrm{min}$ up to $280^{\circ} \mathrm{C}$ and held for 2 min. Electrospray spectra were obtained at $70 \mathrm{eV}$ at $230^{\circ} \mathrm{C}$. Limulus Amebocyte Lysate (LAL) assays were performed by Charles River laboratory (Ecully, France) to determine the endotoxin level in HMW GY785 EPS before and after purification.

c. Characterization of GY785 EPS batches: Monosaccharide content was determined by GC analysis of trimethylsilyl derivatives after acidic methanolysis (Kamerling et al. 1975). The total sulfur content present in the HMW GY785 EPS was determined using high-performance anion-exchange chromatography (HPAEC), as described by Chopin et al. (Chopin et al. 2015). The molecular weight (Mw) of the samples was determined by High-Performance Size Exclusion Chromatography (HPSEC) coupled online with a multi-angle light scattering detector (MALS, Dawn Heleos-IITM, Wyatt) and a differential refractive index (RI) detector (Optilab Wyatt). Data were analyzed with Astra software 6.1 (Wyatt Technology). The mass recovery $(\%)$ and calculated mass $(\mu \mathrm{g})$ evaluated by RI detection are given in the ASTRA report. For each injected EPS sample, this recovery is above $70 \%$.

d. Characterization of other biological molecules: The protein content was determined using the BCA (bicinchoninic acid) protein assay using the BCA1-1KT kit (Sigma). The nucleic acid content was determined using the Quant-iT PicoGreen dsDNA kit (Invitrogen Molecular Probes).

e. SDS-PAGE: Precast polyacrylamide 4 to $20 \%$ gradient gels (Bio-Rad) were used for SDS-PAGE analysis. The E. coli strain O111:B4 LPS was used again as reference. Samples were mixed 4:1 (v/v) with a sample loading buffer $(66 \mathrm{mM}$ Tris- $\mathrm{HCl} \mathrm{pH}$ 6.8, 20\% v/v glycerol, $2 \%$ v/v SDS, $5 \mathrm{mM}$ EDTA, 14.3 M mercaptoethanol, $0.025 \% \mathrm{w} / \mathrm{v}$ bromophenol blue) and boiled for $10 \mathrm{~min}$. $25 \mu \mathrm{g}$ of the sample was loaded on a gel. Gels were run in a buffer composed of $50 \mathrm{mM}$ Tris, $383 \mathrm{mM}$ glycine and $10 \%$ SDS, at 100 V. LPS were detected by silver nitrate staining (Kittelberger et al. 1993, Zhu et al. 2012). 
After this first coloration, SDS-PAGE was further stained with Stains All to detect anionic polysaccharides (Rigouin et al. 2009).

\section{Results}

Characterization of LPS extracted from bacterial cells

LPS were extracted from dried bacterial cells following hot phenol/water (PW) and phenol/chloroform/petroleum ether (PCP) methods. Extracted molecules were first characterized by SDS-PAGE with a double coloration. A highly sensitive silver nitrate staining was used to detect LPS that stain brown (Fig. 2a) and was followed by Stains-All staining that allows visualization and identification of acidic molecules such as acidic proteins and anionic polysaccharides, as blue bands (Fig. 2b). The silver/Stains-All protocol can be used for detection of molecules over a range from 0.25 to $50 \mathrm{ng}$ (Kittelberger et al. 1993, Goldberg et al. 1997). The E. coli LPS (O111:B4 strain) used as reference stained brown and displayed a ladder-like band pattern (Fig. 2, lanes 1). The extract obtained by the PW method showed in the aqueous phase a strong blue broad band at the top of the gel and a strong brown broad band at the bottom (Fig.2b, lane 2), while in the phenolic phase it showed only one dark-brown sharp band at the bottom (Fig.2, lanes 3). The extract obtained by the PCP method displayed in the aqueous phase a brown lightly stained smear and a light-brown broad band at the bottom (Fig.2, lanes 4) and no band in the phenolic phase (Fig.2, lanes 5). Whatever the extraction method used, the displayed brown bands in the LMW region of the gel (bottom) could correspond to LPS present in A. infernus cell membranes. Unlike E. coli (strain O111:B4) LPS, the A. infernus LPS did not display a ladder-like pattern generally observed for Smooth-type LPS, in which the lipid domain called lipid A is linked through a core oligosaccharide to an O-chain or O-antigen domain composed of an oligosaccharidic sequence. Thus, $A$. infernus LPS could be of Rough-type lacking O-chain or displaying a short O-chain LPS. The broad blue band observed in the aqueous phase of the extract obtained with the PW method could correspond to a contaminant HMW EPS that stains blue with Stains-All. Consequently the PW method does not appear to be sufficiently selective for the extraction of A. infernus LPS and the PCP extraction method seems more appropriate for the extraction of A. infernus LPS, which was found only in the aqueous phase (Fig.2, lanes 4). Therefore, both monosaccharide and fatty acid compositions were determined by GC/MS in the dried PCP aqueous phase extract. In parallel, the GC/MS analysis was performed on a commercial E. coli LPS, used as reference (Fig.3). The structure of the commercial E. coli LPS is well known. The main constituents characterizing E. coli LPS, such as 3-deoxy-D-manno-oct-2-ulopyranosonic acid (Kdo), glucosamine $(\mathrm{GlcN})$ and 3-hydroxy-fatty acids were well detected (Stenutz et al. 2006). In contrast, neither Kdo nor GlcN were detected in PCP extract of $A$. infernus cells (Fig.3). The monosaccharide analysis of the dried PCP extract showed the presence of only few sugar residues (Table 1), glucose (Glc), mannose (Man) and N-acetyl-glucosamine (GlcNAc) were the main detected monosaccharides. The fatty acids were identified in small amount as myristic acid C14:0, 3OH-C14:0, palmitic acid C16:0, hexadecenoic acid C16:1, heptadecanoic acid C17:0, stearic acid C18:0 and octadecenoic acid C18:1. The elemental analysis of the PCP extract allowed to determine the presence of a very small amount of phosphorus (P) lower than that of LPS (usually close to 4\%), which suggests that the extract contains most likely phosphorylated molecules such as nucleic acids (Fensom and Gray, 1969). The absence of sulfur (S) confirms that the PCP extract was not contaminated by the sulfated EPS. Therefore, the chemical composition 
of the PCP extract suggests the presence of either atypical LPS or glycolipids in the outer cell membrane of $A$. infernus.

Characterization of LPS in GY785 EPS batches

After the fermentation step, the HMW GY785 EPS was isolated from the bacterial culture by alcoholic precipitation or ultrafiltration. Three batches were analyzed by LAL assays (Charles River Laboratory) and all three displayed a high content of endotoxins, estimated at 40,000, 72,500 and 200,000 EU/mg. The HMW GY785 EPS were then analyzed by SDS-PAGE to detect LPS contamination using silver/Stains-All staining (Fig. 4a and 4b). All HMW GY785 EPS showed a strong blue broad band at the top of the gel and two or three brown thin bands at the bottom (Fig.4b, lanes 3 to 5). The presence or intensity of these latter bands could not be correlated to the degree of contamination. As observed above, the LPS found in HMW GY785 EPS did not present the same ladder pattern as E. coli LPS (lanes 3 to 5). These silver positive LMW bands found in all highly contaminated EPS could correspond to a Rough-type LPS lacking O-antigen moieties, as suggested above for the LPS extracted from the A. infernus bacterial culture (Maskell 1991). Another batch was treated with hydrogen peroxide in order to eliminate LPS. This batch showed a blue stained smear with a higher migration than that observed for the HMW GY785 EPS batches and corresponding to a population of chains with a lower molecular weight (Fig.4b, lane 2). It is important to note however that hydrogen peroxide is commonly used to depolymerize polysaccharides. In this low contaminated LMW EPS as determined by the LAL assays (135 EU/mg), no dark brown band was detected.

Search for an effective method to obtain GY785 EPS free of LPS

As the amount of LPS remained still higher than the level authorized by the European Pharmacopoeia $(<0.5$ EU/mg) in all EPS batches, the development of a rapid and efficient downstream purification method was necessary. For this purpose, a highly LPS contaminated EPS batch was selected for purification assays and analysed. GC/MS chromatograms showed that the GY785 EPS was constituted mainly of sugars (51\% w/w) corresponding to its typical monosaccharide composition with a small amount of proteins (2.6\% w/w), nucleic acids $(7.5 \% \mathrm{w} / \mathrm{w})$ and fatty acids $(0.5 \% \mathrm{w} / \mathrm{w}$ total FAMES), among which myristic acid C14:0, palmitic acid C16:0, hexadecenoic acid C16:1, heptadecanoic acid C17:0, stearic acid C18:0 and octadecenoic acid C18:1 (Table 2). The fatty acid composition of GY785 EPS was similar to LPS composition found in PCP dried extract (Table 1) suggesting that the EPS batch was contaminated by the outer cell membrane LPS or glycolipids.

In order to efficiently purify the GY785 EPS from all contaminating molecules without reducing the polysaccharide molecular weight and modifying its original monosaccharide composition, different methods described in the literature were tested except hydrogen peroxide treatment. To assess the efficacy of different treatments, the amount of the total FAMES and EPS molecular weight before and after detoxification were determined and compared (Table 3). Since endotoxins are negatively charged due to the presence of phosphate groups, anion-exchange chromatography is often employed as a mean to remove them. Two factors govern the success of this approach: $(i)$ the affinity of the endotoxins for the EPS molecule and (ii) the affinity of the endotoxins for the particular anion exchange support used. DEAE-Sephadex chromatography was reported to 
efficiently remove LPS from proteins (Hou et al. 1990). However, the anion-exchange chromatography was not suitable for LPS purification from GY785 EPS since the GY785 EPS, which is an acidic polysaccharide due to the presence of uronic sugars and sulfate groups, was recovered only at $75 \%$, which suggests a slight binding to the column. The endotoxin level was reduced to only $17 \%$. Affinity chromatography (NoEndo resin), commonly used for high binding affinity of the lipid A moiety of LPS, allowed to remove around $88 \%$ and $80 \%$ of the LPS from GY785 EPS using a column and in batch, respectively. The low efficiency of NoEndo resin was attributed to a too high level of endotoxins, which results in an overloading of the resin. Because of their amphiphilic structure, LPS have poor solubility in aqueous solutions and are present as aggregates in colloidal solution. The physical state of LPS depends on the polysaccharide moiety of the LPS and also on the presence of inorganic cations and basic amines, which neutralize negatively charged groups on LPS and induce their aggregation (Garidel et al. 2005). Bligh and Dyer extraction method using organic solvents, i.e. a chloroform/methanol mixture was applied to remove LPS from the EPS sample (Bligh et al. 1959). A decrease in the total FAMES was observed, indicating that the lipid molecules are extractable in organic phase in a liquid/liquid extraction. After performing three cycles of extraction, a level of the residual FAMES of 7\% was obtained. However, the recovery yield of the EPS obtained by alcohol precipitation from the aqueous phase was only of $66 \%$.

In order to prevent self-aggregation of LPS, surfactants such as Triton X-114 (Adam et al. 1995, Mercaldi et al. 2008) or sodium deoxycholate (NaDOC) (Shands et al. 1980, Kachlany et al. 2001) may be added. Although, the LPS level was reduced by $91 \%$ by performing three cycles of Triton X-114 extraction, the treatment led to EPS recovery of only $50 \%$. In contrast, the NaDOC extraction allowed to remove $99.5 \%$ of the total FAMES from GY785 EPS, which was recovered at $75 \%$. The main characteristics of the EPS obtained after the NaDOC treatment are reported in Table 4. Before the treatment, $1 \mathrm{mg}$ of GY785 EPS was contaminated at a microgram level by proteins and fatty acids (total FAMES) and at a nanogram level with nucleic acids (Table 2). The

purified EPS was free of protein and the amount of nucleic acids was significantly decreased (down to $0.002 \%$ $\mathrm{w} / \mathrm{w})$. After the NaDOC treatment, only very low quantity $(0.002 \% \mathrm{w} / \mathrm{w})$ of palmitic acid $(16: 0)$ was detected. LAL assays performed on the purified EPS sample revealed a residual LPS amount of $55 \mathrm{EU} / \mathrm{mg}$. Only minor modifications of the sugar composition and sulfur content of the GY785 EPS were noticed.

\section{Discussion}

In comparison to the indicative data of Leone et al. (Leone et al. 2007), no LPS comparable to those extracted from other Alteromonas strains was found in the A. infernus bacterium. Indeed, although at the first sight, the SDS-PAGE data seem to prove the presence of Rough-type LPS in the A. infernus strain, all samples extracted by the common phenol-chloroform-petroleum ether method and characterized by GC/MS were shown to lack the typical lipid A or the core of LPS. In some cases, the absence of Kdo, or even a modification of the lipid A backbone amino sugar are observed (Caroff et al. 2003). The absence of Kdo, glucosamine and phosphorylated monosaccharides which are ubiquitous constituents of all LPS demonstrates the uncommon structure of $A$. infernus membrane lipids.

The lack of LPS in a Gram-negative bacterium is not an exception. Indeed, several Gram-negative bacteria do not contain LPS at all, such as Chloroflexus aurantiacus (Meissner et al. 1988) or Thermus thermophilus (Silipo et al. 2004). Bacteria of the genus Sphingomonas were shown to have glycosphingolipids that fulfill the LPS function (Kawahara et al. 1991, Kawasaki et al. 1994). Schultz et al. reported the extraction of a new class of 
outer membrane lipid which was isolated from Treponema denticola by phenol-chloroform-petroleum ether extraction; this glycolipid probably functions as LPS but lacks Kdo and 3-hydroxy-fatty acids (Schultz et al. 1998). Therefore, there are some species of Gram-negative bacteria, which despite the absence of LPS, continue to propagate and accomplish normal life cycle. However, it is for the first time that the lack of a typical LPS is reported for an Alteromonas strain. Liparoti et al. (Liparoti et al. 2006) and Leone et al. (Leone et al. 2007) have proposed a Rough-type LPS in A. macleodii ATCC 27126 and A. addita KMM 3600, respectively. However in these studies, the extraction by the conventionally adopted phenol-chloroform-petroleum ether method resulted in a glycolipid or a phosphoglycolipid recovery instead of LPS. A. macleodii ATCC 27126 and A. addita KMM 3600 strains were isolated from surface sea water samples collected from around the Hawaiian Islands and the region of Chazma Bay (Sea of Japan), respectively whereas A. infernus GY785 strain was collected in the deep sea of the Southern depression of the Guaymas basin. Silipo et al. were interested in LPS from Thermus thermophilus HB8 strain (Silipo et al. 2004). This halotolerant bacterium, which was isolated from shallow marine hot spring in Japan, is able to grow in harsh environmental conditions of temperature reaching $80^{\circ} \mathrm{C}$. The authors reported that the outer membrane of this bacterium was not composed of LPS, which was totally absent, but of a glycolipid, which could substitute the LPS in the structure of the external membrane. Similar results were reported in Leone et al. for Thermus thermophilus Samu-SA1 strain, also isolated from a shallow marine hot spring (Leone et al. 2006). Consequently, these authors suggested that microbial adaptation to hard habitats has been accomplished through the biosynthesis of molecules with uncommon negative charge density in the outer membrane (i.e. phosphate groups and acidic monosaccharides) which could have the structural function of LPS.

To our knowledge, no structure of LPS from bacteria isolated from deep-sea ecosystem has been published to date. Sledjeski and Weiner only reported the analysis by SDS-PAGE of several LPS from marine bacteria, including the analysis of LPS from three hydrothermal vent Hyphomonas strains (Sledjeski et al. 1991). These three LPS appeared to be Rough-type LPS with a lack of ladder-like pattern. On SDS-PAGE, all three have a slightly stained band migrating immediately after another more darkly stained one, the same profile was observed for the extracts of A. infernus which could suggest the presence of similar molecule type. Mining the genome sequence of A. infernus for potential genetic clusters of lipidic and glycosidic polymers could later confirm the presence of genes coding for an atypical LPS or glycolipids. This method was previously described by Keck et al. to demonstrate the absence of LPS in the Sorangium cellulosum strain So ce56 (Keck et al. 2011). Different detoxification and purification methods were applied to obtain A. infernus GY785 EPS free of endotoxins. DEAE-Sephadex chromatography is a method reported to efficiently remove LPS from proteins (Hou et al. 1990). Suwan et al. (Suwan et al. 2012) have reported that anion-exchange chromatography was efficient to remove endotoxins from heparosan (a non-sulfated precursor of heparin), but not from sulfated heparin. The inefficiency was attributed to the binding of heparin to DEAE due to the low pKa value of the sulfate groups. In contrast to these methods, we have shown that a treatment based on the differential solubility of EPS and LPS in NaDOC detergent was more efficient. NaDOC treatment was rapid and allowed both to purify at high level the HMW GY785 EPS while preserving its structure. This method is therefore a promising alternative to totally eliminate proteins and to reduce both glycolipid components and nucleic acid contents at a nanogram level from the GY785 EPS. 
Acknowledgements Financial supports were provided by the "BIOREGOS" network in Pays de la Loire area and "IONIBIOGEL" ANR Blanc SIMI 9 (ANR, Agence Nationale de la Recherche, France).

Ethical statement and conflict of interest Authors accept the rules of good scientific practice and agree with the COPE guidelines followed by the Applied Microbiology and Biotechnology Journal. Authors declare that they have no conflict of interest.

\section{References}

Adam O, Vercellone A, Paul F, Monsan PF, Puzo G (1995) A Nondegradative Route for the Removal of Endotoxin from Exopolysaccharides. Anal. Biochem. 225(2): 321-327.

Anspach FB, Hilbeck O (1995) Removal of endotoxins by affinity sorbents. J Chromatogr. A 711(1): 81-92.

Bligh EG, Dyer WJ (1959) A rapid method of total lipid extraction and purification. Can. J Biochem. Physiol. 37(8): 911-917.

Bohin A, Bouchart F, Richet C, Kol O, Leroy Y, Timmerman P, Huet G, Bohin J-P, Zanetta J-P (2005) GC/MS identification and quantification of constituents of bacterial lipids and glycoconjugates obtained after methanolysis as heptafluorobutyrate derivatives. Anal. Biochem. 340(2): 231-244.

Caroff M, Karibian D (2003) Structure of bacterial lipopolysaccharides. Carbohydr. Res. 338(23): 2431-2447.

Chopin N, Sinquin C, Ratiskol J, Zykwinska A, Weiss P, Cerantola S, Le Bideau J, Colliec-Jouault S (2015) A Direct Sulfation Process of a Marine Polysaccharide in Ionic Liquid. Biomed Res. Int. 2015: 508656. doi:.

Colliec-Jouault S, Zanchetta P, Helley D, Ratiskol J, Sinquin C, Fischer AM, Guezennec J (2004) Exopolysaccharides produced by bacteria isolated from deep-sea hydrothermal vents: new agents with therapeutic potential. Pathol. Biol. 52(3): 127-130.

Delbarre-Ladrat C, Sinquin C, Lebellenger L, Zykwinska A, Colliec-Jouault S (2014) Exopolysaccharides produced by marine bacteria and their applications as glycosaminoglycan-like molecules. Front. Chem. 2: $85-85$.

Fensom AH, Gray GW (1969) The Chemical Composition of Lipopolysaccharide of Pseudomonas aeruginosa. Biochem J. 114, 185-196.

Galanos C, Luderitz O, Westphal O (1969) A new method for the extraction of R lipopolysaccharides. Eur. J Biochem. / FEBS 9(2): 245-249.

Garidel P, Rappolt M, Schromm AB, Howe J, Lohner K, Andra J, Koch MHJ, Brandenburg K (2005) Divalent cations affect chain mobility and aggregate structure of lipopolysaccharide from Salmonella minnesota reflected in a decrease of its biological activity. Biochim. Biophys. Acta-Biomembr. 1715(2): 122-131.

Goldberg HA, Warner KJ (1997) The Staining of Acidic Proteins on Polyacrylamide Gels: Enhanced Sensitivity and Stability of "Stains-All" Staining in Combination with Silver Nitrate. Anal. Biochem. 251(2): 227-233.

Guezennec J (2002) Deep-sea hydrothermal vents: A new source of innovative bacterial exopolysaccharides of biotechnological interest? J. Ind. Microbiol. Biotechnol. 29: 204-208.

Heymann D, Ruiz-Velasco C, Chesneau J, Ratiskol J, Sinquin C, Colliec-Jouault S (2016) Anti-Metastatic Properties of a Marine Bacterial Exopolysaccharide-Based Derivative Designed to Mimic Glycosaminoglycans. Molecules 21(3): 309.

Hou KC, Zaniewski R (1990) Endotoxin removal by anion-exchange polymeric matrix. Biotechnol. Appl. Biochem. 12(3): 315-324.

Kachlany SC, Levery SB, Kim JS, Reuhs BL, Lion LW, Ghiorse WC (2001) Structure and carbohydrate analysis of the exopolysaccharide capsule of Pseudomonas putida G7. Environ. Microbiol. 3(12): 774-784.

Kamerling JP, Gerwig GJ, Vliegenthart JF, Clamp JR (1975) Characterization by gas-liquid chromatographymass spectrometry and proton-magnetic-resonance spectroscopy of pertrimethylsilyl methyl glycosides obtained in the methanolysis of glycoproteins and glycopeptides. Biochem. J 151(3): 491-495.

Kawahara K, Seydel U, Matsuura M, Danbara H, Rietschel ET, Zahringer U (1991) Chemical-Structure of Glycosphingolipids isolated from Sphingomonas-paucimobilis. Febs Letters 292(1-2): 107-110.

Kawasaki S, Moriguchi R, Sekiya K, Nakai T, Ono E, Kume K, Kawahara K (1994) The Cell-envelope Structure of the Lipopolysaccharide-lacking Gram-negative Bacterium Sphingomonas-paucimobilis. J. Bacteriol. 176(2): 284-290.

Keck M, Gisch N, Moll H, Vorhoelter F-J, Gerth K, Kahmann U, Lissel M, Lindner B, Niehaus K, Hoist O (2011) Unusual Outer Membrane Lipid Composition of the Gram-negative, Lipopolysaccharide-lacking Myxobacterium Sorangium cellulosum So ce56. Journal of Biological Chemistry 286(15): 12850-12859.

Kittelberger R, Hilbink F (1993) Sensitive silver-staining detection of bacterial lipopolysaccharides in polyacrylamide gels. J Biochem. Biophys. Methods 26(1): 81-86. 
Laurienzo P (2010) Marine polysaccharides in pharmaceutical applications: an overview. Mar. Drugs 8(9): $2435-2465$

Leone S, Molinaro A, Lindner B, Romano I, Nicolaus B, Parrilli M, Lanzetta R, Holst O (2006) The structures of glycolipids isolated from the highly thermophilic bacterium Thermus thermophilus Samu-SA1. Glycobiology 16(8): 766-775.

Leone S, Molinaro A, Sturiale L, Garozzo D, Nazarenko EL, Gorshkova RP, Ivanova EP, Shevchenko LS, Lanzetta R, Parrilli M (2007) The Outer Membrane of the Marine Gram-Negative Bacterium Alteromonas addita is Composed of a Very Short-Chain Lipopolysaccharide with a High Negative Charge Density. Eur. J. Org. Chem. 2007(7): 1113-1122.

Liparoti V, Molinaro A, Sturiale L, Garozzo D, Nazarenko EL, Gorshkova RP, Ivanova EP, Shevcenko LS, Lanzetta R, Parrilli M (2006) Structural analysis of the deep rough lipopolysaccharide from gram negative bacterium Alteromonas macleodii ATCC 27126(T): The first finding of beta-Kdo in the inner core of lipopolysaccharides. Eur. J. Org. Chem.(20): 4710-4716.

Magalhaes PO, Lopes AM, Mazzola PG, Rangel-Yagui C, Penna TCV, Pessoa A, Jr. (2007) Methods of endotoxin removal from biological preparations: a review. J. Pharm. Pharm. Sci. 10(3): 388-404.

Maskell JP (1991) The resolution of bacteroides lipopolysaccharides by polyacrylamide gel electrophoresis. J. Med. Microbiol. 34(5): 253-257.

McIntire FC, Sievert HW, Barlow GH, Finley RA, Lee AY (1967) Chemical, physical, biological properties of a lipopolysaccharide from Escherichia coli K-235. Biochem. 6(8): 2363-2372.

Meissner J, Krauss JH, Jurgens UJ, Weckesser J (1988) Absence of a characteristic cell-wall lipolysaccharide in the phototrophic bacterium Chloroflexus-aurantiacus. J Bacteriol. 170(7): 3213-3216.

Mercaldi MP, Dams-Kozlowska H, Panilaitis B, Joyce AP, Kaplan DL (2008) Discovery of the dual polysaccharide composition of emulsan and the isolation of the emulsion stabilizing component. Biomacromolecules 9(7): 1988-1996.

Merceron C, Portron S, Vignes-Colombeix C, Rederstorff E, Masson M, Lesoeur J, Sourice S, Sinquin C, Colliec-Jouault S, Weiss P, Vinatier C, Guicheux J (2012) Pharmacological modulation of human mesenchymal stem cell chondrogenesis by a chemically oversulfated polysaccharide of marine origin: potential application to cartilage regenerative medicine. Stem cells (Dayton, Ohio) 30(3): 471-480.

Pier GB, Sidberry HF, Zolyomi S, Sadoff JC (1978) Isolation and characterization of a high-molecular-weight polysaccharide from the slime of Pseudomonas aeruginosa. Infect. Immun. 22(3): 908-918.

Rigouin C, Delbarre Ladrat C, Sinquin C, Colliec-Jouault S, Dion M (2009) Assessment of biochemical methods to detect enzymatic depolymerization of polysaccharides. Carbohydr. Polym. 76(2): 279-284.

Roger O, Kervarec N, Ratiskol J, Colliec-Jouault S, Chevolot L (2004) Structural studies of the main exopolysaccharide produced by the deep-sea bacterium Alteromonas infernus. Carbohydr. Res. 339: 23712380.

Rougeaux H, Kervarec N, Pichon R, Guezennec J (1999) Structure of the exopolysaccharide of Vibrio diabolicus isolated from a deep-sea hydrothermal vent. Carbohydr. Res. 322(1-2): 40-45.

Schultz CP, Wolf V, Lange R, Mertens E, Wecke J, Naumann D, Zahringer U (1998) Evidence for a new type of outer membrane lipid in oral spirochete Treponema denticola - Functioning permeation barrier without lipopolysaccharides. J Biol. Chem. 273(25): 15661-15666.

Shands JW, Chun PW (1980) The dispersion of gram-negative lipopolysaccharide by deoxycholate. Subunit molecular weight. J Biol. Chem. 255(3): 1221-1226. doi:.

Silipo A, Molinaro A, De Castro C, Ferrara R, Romano I, Nicolaus B, Lanzetta R, Parrilli M (2004) Structural analysis of a novel polysaccharide of the lipopolysaccharide-deficient extremophile gram-negative bacterium Thermus thermophilus HB8. Eur. J. Org. Chem.(24): 5047-5054.

Sledjeski DD, Weiner RM (1991) Hyphomonas spp, Shewanella spp, and other marine-bacteria lack heterogeneous (ladderlike) lipolysaccharides. Applied and Environmental Microbiology 57(7): 2094-2096.

Stenutz R, Weintraub A, Widmalm G (2006) The structures of Escherichia coli O-polysaccharide antigens. FEMS Microbiol. Rev. 30(3): 382-403.

Suwan J, Torelli A, Onishi A, Dordick JS, Linhardt RJ (2012) Addressing endotoxin issues in bioengineered heparin. Biotechnol. Appl. Biochem. 59(6): 420-428.

Tirsoaga A, El Hamidi A, Perry MB, Caroff M, Novikov A (2007) A rapid, small-scale procedure for the structural characterization of lipid A applied to Citrobacter and Bordetella strains: discovery of a new structural element. J. Lipid Res. 48(11): 2419-2427.

Wang X, Quinn PJ (2010) Endotoxins: lipopolysaccharides of gram-negative bacteria. Subcell. Biochem. 53: 325.

Wilson MJ, Haggart CL, Gallagher SP, Walsh D (2001) Removal of tightly bound endotoxin from biological products. J Biotechnol. 88(1): 67-75.

Zhu Z-X, Cong W-T, Ni M-W, Wang X, Ma W-D, Ye W-J, Jin L-T, Li X-K (2012) An improved silver stain for the visualization of lipopolysaccharides on polyacrylamide gels. Electrophoresis 33(7): 1220-1223. 
Table 1 Chemical composition of the PCP extract obtained from A.infernus dried cells

\begin{tabular}{cc}
$\begin{array}{c}\text { Monosaccharide and } \\
\text { Fatty Acids }\end{array}$ & $(\% \mathrm{w} / \mathrm{w})$ \\
\hline Glc & \\
Man & 1.7 \\
Gal & 1.2 \\
Rha & 0.3 \\
GlcN & 0.04 \\
GlcNAc & nd \\
GalA & 2.1 \\
Kdo & 0.4 \\
C12:00 & nd \\
C14:0 & 0.08 \\
3OH-C14:0 & 0.03 \\
C16:1 $16: 0$ & 0.17 \\
C17:0 & 0.13 \\
C18:1 & 0.18 \\
C18:0 & 0.07 \\
P & 0.09 \\
S & 0.08 \\
\hline
\end{tabular}

nd: not detected

Table 2 Chemical composition of the native GY785 EPS

\begin{tabular}{|c|c|}
\hline & Native GY785 EPS \\
\hline Endotoxins (EU/mg) & 72,500 \\
\hline Sugar composition & Rha/Man/Glc/Gal/GlcA/GalA \\
\hline Sugar content $(\% \mathrm{w} / \mathrm{w})$ & $1 / 2 / 18 / 15 / 9 / 6$ \\
\hline Sulfur $(\% \mathrm{w} / \mathrm{w})$ & 4.5 \\
\hline Protein $(\% \mathrm{w} / \mathrm{w})$ & 2.6 \\
\hline Nucleic acid (\% w/w) & 0.007 \\
\hline FAMES composition & 3ОH-C14:0/16:1/16:0/18:1/18:0 \\
\hline FAMES $(\% \mathrm{w} / \mathrm{w})$ & $0.02 / 0.04 / 0.15 / 0.2 / 0.02$ \\
\hline Total FAMES (\% w/w) & 0.43 \\
\hline $\mathrm{Mw}(\mathrm{g} / \mathrm{mol}) / \mathrm{Mn}(\mathrm{g} / \mathrm{mol}) / \mathrm{Ip}^{\mathrm{a}}$ & $2.1 \times 10^{6} / 1.9 \times 10^{6} / 1.1$ \\
\hline
\end{tabular}


Table 3 Fatty acid (total FAMES), GY785 EPS recovery yield and EPS molecular weight before and after different purification treatments.

\begin{tabular}{lccc}
\multicolumn{1}{c}{ Treatment applied } & $\begin{array}{c}\text { Total FAMES } \\
\text { yield } \\
(\% \mathrm{w} / \mathrm{w})\end{array}$ & $\begin{array}{c}\text { EPS yield } \\
(\% \mathrm{w} / \mathrm{w})\end{array}$ & $\begin{array}{c}\text { SEC-MALS } \\
(\mathrm{Mw} / \mathrm{Mn} / \mathrm{Ip})\end{array}$ \\
\hline No treatment & 100 & 100 & $2.1 \times 10^{6} / 1.9 \times 10^{6} / 1.1$ \\
Anion-exchange chromatography & 83 & 75 & $2.1 \times 10^{6} / 1.9 \times 10^{6} / 1.1$ \\
Affinity chromatography (column) & 12 & 23 & $2.1 \times 10^{6} / 1.9 \times 10^{6} / 1.1$ \\
Affinity chromatography (batch) & 20 & 84 & $2.1 \times 10^{6} / 1.9 \times 10^{6} / 1.1$ \\
Chloroform/methanol extraction & 7 & 66 & $1.8 \times 10^{6} / 7.2 \times 10^{5} / 2.5$ \\
Triton X-114 & 9 & 34 & $2.1 \times 10^{6} / 1.9 \times 10^{6} / 1.1$ \\
NaDOC & 0.5 & 75 & $2.2 \times 10^{6} / 1.5 \times 10^{6} / 1.5$ \\
\hline
\end{tabular}

${ }^{\mathrm{a}}$ Mw: weight-average molecular weight, Mn: number-average molecular weight and Ip:

Mw/Mn polydispersity index

Table 4 Chemical composition and molecular weight of the GY785 EPS after the NaDOC treatment

\begin{tabular}{lc}
\hline & $\begin{array}{c}\text { GY785 EPS after } \\
\text { NaDOC treatment }\end{array}$ \\
\hline Endotoxins (EU/mg) & 55 \\
Sugar composition & Rha/Man/Glc/Gal/GlcA/GalA \\
Sugar content (\% w/w) & $1 / 2 / 14 / 15 / 10 / 7$ \\
Sulfur (\% w/w) & 4.3 \\
Protein $(\%$ w/w) & 0 \\
Nucleic acid (\% w/w) & 0.002 \\
FAMES composition & $16: 0$ \\
Total FAMES (\% w/w) & 0.002 \\
Mw (g/mol)/Mn (g/mol)/Ip ${ }^{a}$ & $2.23 \times 10^{6} / 1.52 \times 10^{6} / 1.5$ \\
\hline${ }^{a}$ Mw: weight-average molecular weight, Mn: number-average molecular weight \\
and Ip: Mw/Mn polydispersity index
\end{tabular}




\section{Figures}

Fig. 1 Nonasaccharidic repeating unit of GY785 EPS composed of: 4 glucose (Glc), 2 galactose (Gal), 2 glucuronic acids (GlcA) and 1 galacturonic acid (GalA) residues. GalA bears one sulfate group at $\mathrm{C} 2$ position (Roger et al, 2004)

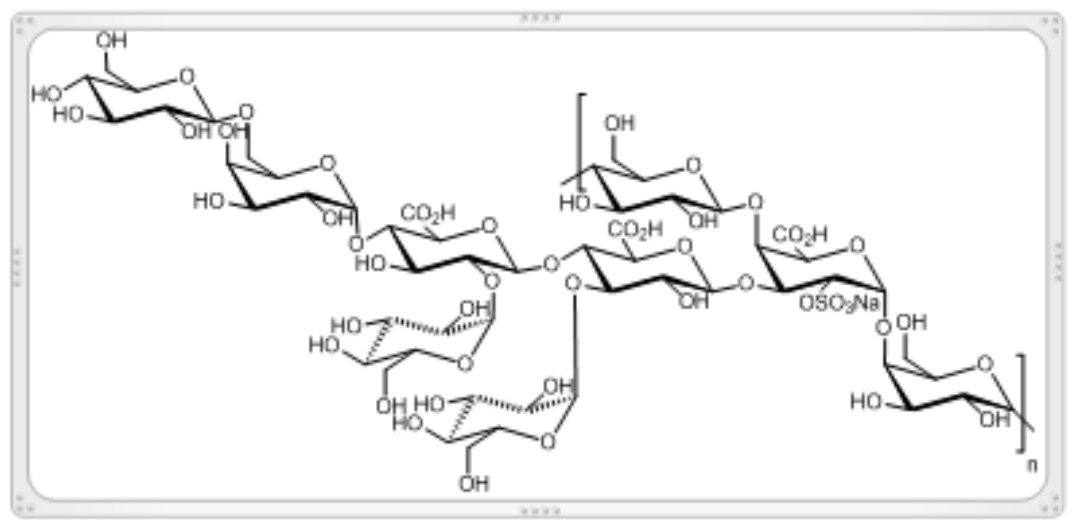


Fig. 2 SDS-PAGE analysis of A. infernus cell extracts after silver nitrate (a) and silver nitrate and Stains-All (b) stainings. Lane 1 contains E. coli O111:B4 LPS as control. Lanes 2 to 5 are extracts obtained from A. infernus dried cells: lanes 2 and 3, molecules extracted by the phenol-water (PW) method in aqueous phase and phenolic phase, respectively, lanes 4 and 5, molecules extracted by the phenol-chloroform-petroleum ether (PCP) method, in aqueous phase and phenolic phase, respectively

2

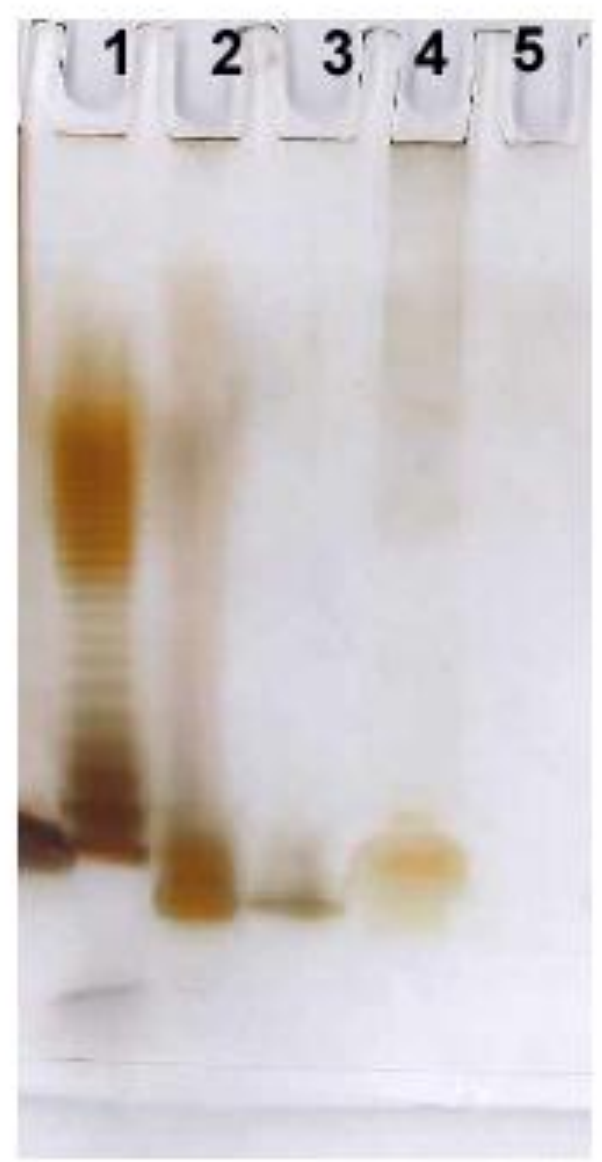

b

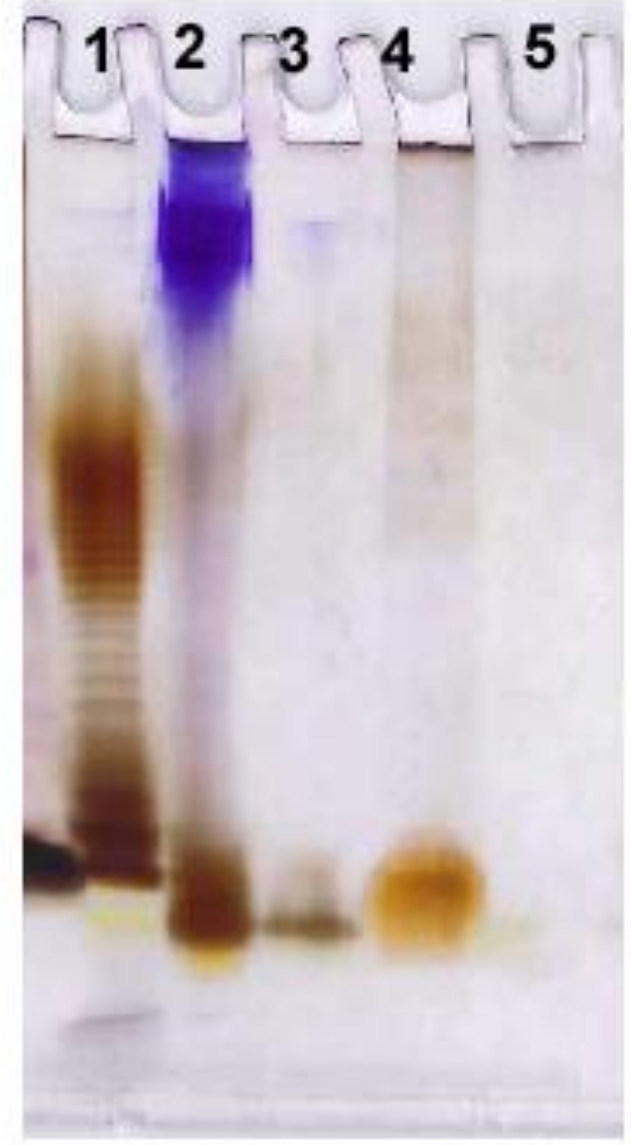


Fig. 3 GC-MS chromatograms of the heptafluorobutyrate derivatives material liberated by acid methanolysis of E. coli LPS from the 026:B6 strain and A. infernus cell extract (aqueous phase of PCP method)
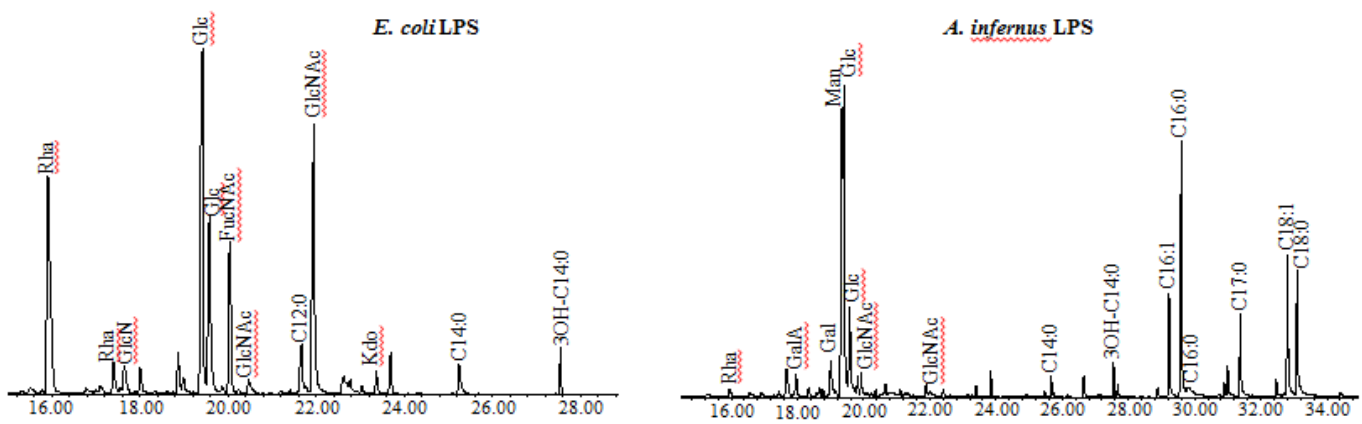
Fig. 4 SDS-PAGE analysis of GY785 EPS stained by silver nitrate (a) and silver nitrate followed by Stains-All (b). Lane 1: E. coli O111:B4 LPS. Lane 2: LMW GY785 EPS (MW = $30 \mathrm{~kg} / \mathrm{mol}$ ) containing $135 \mathrm{EU} / \mathrm{mg}$ of endotoxins. Lanes 3, 4 and 5: HMW GY785 EPS (MW $\approx 2,000 \mathrm{~kg} / \mathrm{mol}$ ) containing 43,000, 72,500 and 200,000 EU/mg of endotoxins, respectively.

a

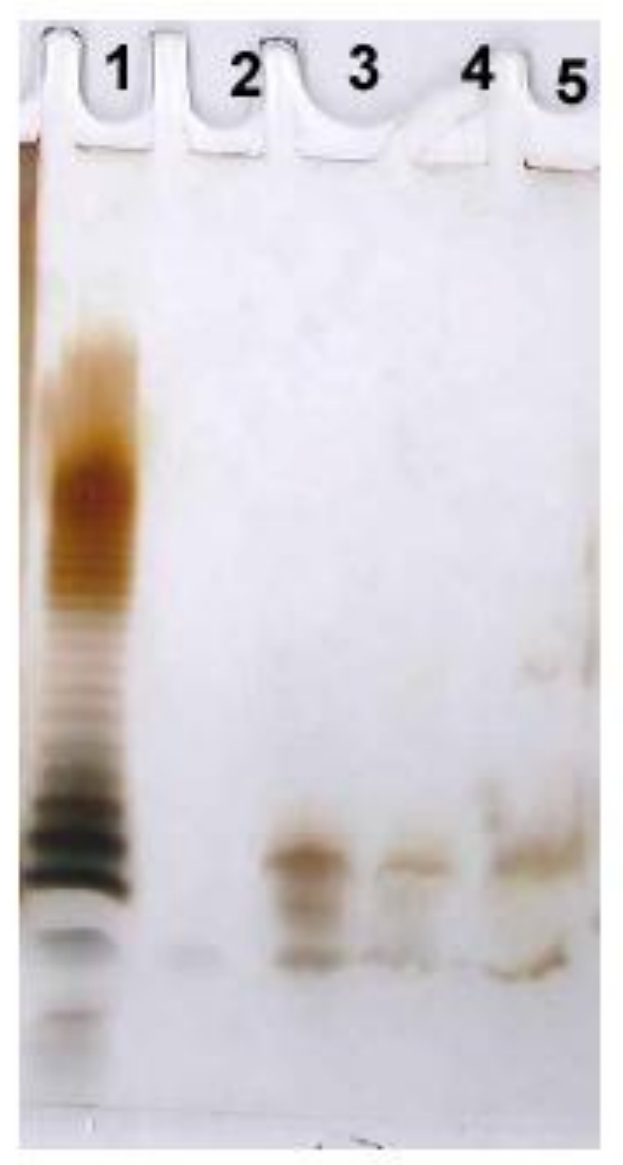

b

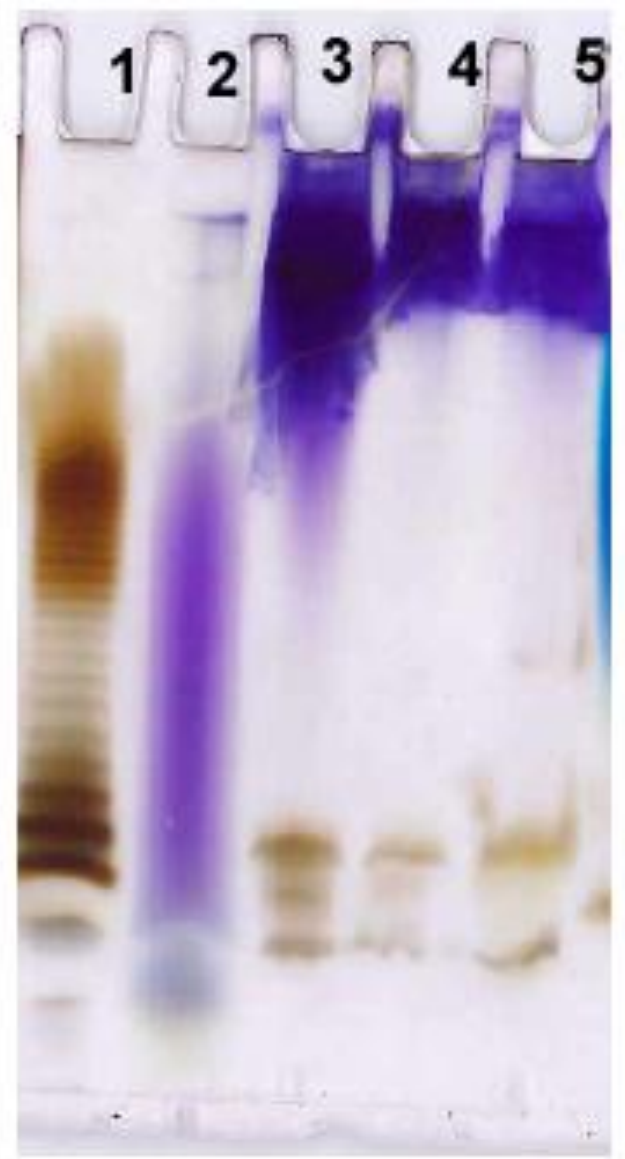

